\title{
Effect of Herpes Simplex Suppression on Incidence of HIV among Women in Tanzania
}

\author{
Deborah Watson-Jones, M.D., Ph.D., Helen A. Weiss, Ph.D., Mary Rusizoka, Dip.Med., John \\ Changalucha, M.Sc., Kathy Baisley, M.Sc., Kokugonza Mugeye, Dip.Med., Clare Tanton, \\ M.Sc., David Ross, M.D., Ph.D., Dean Everett, Ph.D., Tim Clayton, M.Sc., Rebecca Balira, \\ M.Sc., Louise Knight, M.Sc., Ian Hambleton, Ph.D., Jerome Le Goff, M.Sc., Ph.D., Laurent \\ Belec, M.Sc., Ph.D., and Richard Hayes, D.Sc. \\ From the London School of Hygiene and Tropical Medicine, London (D.W.-J., H.A.W., K.B., C.T., \\ D.R., D.E., T.C., L.K., I.H., R.H.); the African Medical and Research Foundation (D.W.-J., M.R., \\ K.M.) and the National Institute for Medical Research (J.C., K.B., C.T., D.E., R.B., L.K., I.H.) - \\ both in Mwanza, Tanzania; and the Laboratoire de Microbiologie, Hôpital Saint Louis (J.L.G.), and \\ INSERM Unité 743 and Université Paris V (L.B.) - both in Paris.
}

\section{Abstract \\ BACKGROUND-Infection with herpes simplex virus type 2 (HSV-2) is associated with an increased risk of acquiring infection with the human immunodeficiency virus (HIV). This study tested the hypothesis that HSV-2 suppressive therapy reduces the risk of HIV acquisition.}

METHODS-Female workers at recreational facilities in northwestern Tanzania who were 16 to 35 years of age were interviewed and underwent serologic testing for HIV and HSV-2. We enrolled female workers who were HIV-seronegative and HSV-2-seropositive in a randomized, double-blind, placebo-controlled trial of suppressive treatment with acyclovir (400 $\mathrm{mg}$ twice daily). Participants attended mobile clinics every 3 months for a follow-up period of 12 to 30 months, depending on enrollment date. The primary outcome was the incidence of infection with HIV. We used a modified intention-to-treat analysis; data for participants who became pregnant were censored. Adherence to treatment was estimated by a tablet count at each visit.

\begin{abstract}
RESULTS-A total of 821 participants were randomly assigned to receive acyclovir (400 participants) or placebo (421 participants); 659 (80\%) completed follow-up. Mean follow-up for the acyclovir and placebo groups was 1.52 and 1.62 years, respectively. The incidence of HIV infection was 4.27 per 100 person-years (27 participants in the acyclovir group and 28 in the placebo group), and there was no overall effect of acyclovir on the incidence of HIV (rate ratio for the acyclovir group, $1.08 ; 95 \%$ confidence interval, 0.64 to 1.83 ). The estimated median adherence was $90 \%$. Genital HSV was detected in a similar proportion of participants in the two study groups at 6,12 , and 24 months. No serious adverse events were attributable to treatment with acyclovir.
\end{abstract}

CONCLUSIONS-These data show no evidence that acyclovir (400 mg twice daily) as HSV suppressive therapy decreases the incidence of infection with HIV. (Current Controlled Trials number, ISRCTN35385041.)

Copyright $@ 2008$ Massachusetts Medical Society.

Address reprint requests to Dr. Watson-Jones at the Department of Infectious and Tropical Diseases, Keppel St., London WC1E 7HT, United Kingdom, or at deborah.watson-jones@1shtm.ac.uk..

The investigators and study committees are listed in the Appendix.

No potential conflict of interest relevant to this article was reported.

Preliminary findings from the trial were presented at the International AIDS Society Conference, Sydney, Australia, July 22 to 25 , 2007 and the 17th meeting of the International Society for Sexually Transmitted Disease Research, Seattle, July 29 to August 1, 2007. 
New strategies for the prevention of infection with the human immunodeficiency virus (HIV) are needed, especially in sub-Saharan Africa. The prevalence of HIV infection in people 15 to 49 years of age in Tanzania is estimated at $6.5 \%, 1$ and it reaches $40 \%$ in highrisk groups such as workers in bars and guest-houses,2-4 who may supplement their income by offering sex in return for money or gifts. The use of condoms with clients remains low among these workers, despite intensive educational campaigns, 5 and sexually transmitted infections are highly prevalent, especially infection with the herpes simplex virus type 2 (HSV-2), with a prevalence of up to 80\%.2,4,6 Observational studies suggest that HSV-2 infection doubles or triples the risk of acquiring HIV and may contribute to more than 50\% of HIV infections in sub-Saharan Africa.7,8 In Tanzania, an estimated 74\% of new HIV infections in men, $22 \%$ in women, and $63 \%$ in bar and hotel workers are attributable to HSV-2.9,10 HSV-2 may also be important in the transmission of HIV, and recent randomized, controlled trials of herpes suppressive therapy in HIV-positive subjects have demonstrated reductions in genital and plasma HIV viral load over a 3-month period.11-14

Here we report the results of a randomized, controlled trial to test the hypothesis that herpes suppressive therapy might reduce HIV acquisition. The primary objective of this trial was to determine whether a standard suppressive regimen of acyclovir would reduce the incidence of infection with HIV in an occupational cohort of females in which a high proportion of HIV infections may be attributable to HSV-2.

\section{METHODS \\ PARTICIPANTS}

Females 16 to 35 years of age in 19 communities in northwestern Tanzania who worked in bars, guesthouses, and other food and recreational facilities were invited to attend mobile clinics and were screened for the presence of HSV-2 and HIV antibodies, as described previously.4 After screening, they were invited to return to the clinic approximately 8 to 12 weeks later. To be eligible for enrollment, participants had to be HSV-2-seropositive, 16 to 35 years of age, not pregnant or planning a pregnancy in the next 2 years, and not breastfeeding. They had to reside near a trial site, with no plans to move, and they had to be present at the site at the time of the next scheduled visit. Potential participants who had a seizure disorder or were too unwell to participate were excluded.

Informed consent was obtained in several stages. Group and individual discussions about the trial were held during orientation activities and screening. At enrollment, participants received informational leaflets along with a picture book and an audiocassette tape explaining the aims and procedures of the trial. An eight-question comprehension check was performed; if the key concepts were not understood, they were explained and the questions were asked again. Participants unable to understand the key concepts were not enrolled.

\section{TRIAL PROCEDURES}

After participants had consented in writing or by fingerprint, blood and urine samples were obtained and the urine sample was tested for pregnancy. Participants were asked about their recent sexual behavior and symptoms of sexually transmitted infections. At examination, vaginal and cervical specimens were obtained, and a cervicovaginal lavage using $3 \mathrm{ml}$ of phosphate-buffered saline was performed. Genital ulcers were swabbed. Participants were offered free family planning and syndromic management for sexually transmitted infections.

Participants were randomly assigned to receive either acyclovir (400 $\mathrm{mg}$ twice daily) or matching placebo, using randomly permuted blocks of four, and were given a 4-month supply of study tablets. Participants and the trial team remained unaware of the treatment allocation throughout the trial. 
The mobile clinic team visited each site approximately every 12 weeks. At scheduled visits, participants were interviewed, a 10-ml blood sample was collected, tablets were counted, and additional tablets were issued. Participants were given counseling and advice on adherence. They were tested for pregnancy if their menstrual period was late or if they thought they might be pregnant; pregnant participants stopped taking the study tablets. Pregnant participants and participants who wanted to stop taking the study tablets continued to receive all routine visit procedures except the provision of study tablets unless they asked to completely withdraw from the trial. Vaginal and cervical specimens were obtained and a cervicovaginal lavage was performed at $6,12,24$, and 30 months; a genital examination was performed at other visits in participants who had symptoms. Participants received free treatment for minor medical conditions and were offered voluntary counseling and testing for HIV using rapid tests (Capillus HIV-1/HIV-2 assay [Trinity Biotech] and Abbott Determine assay [Abbott Laboratories]) along with risk-reduction counseling and free condoms. At each visit, participants received 3000 Tanzanian shillings (approximately \$3) as reimbursement for their time.

Approximately 4 weeks after scheduled visits, a mobile adherence-support team visited participants to provide support and adherence counseling and to count remaining tablets. Between the 6- and 9-month scheduled visits, a urine sample and data on the last study tablet taken were also obtained.

At 3, 9, 15, 21, and 27 months, participants were examined only if they had symptoms of a sexually transmitted infection, and they were given syndromic management or treatment of any untreated sexually transmitted infection identified by laboratory testing at their earlier visits. At baseline and at 6,12,18,24, and 30 months, participants were examined and a blood sample was obtained; with the exception of the 18-month visit, vaginal and cervical samples were also obtained, a cervicovaginal lavage was performed, and participants received syndromic treatment.

Adherence to treatment was estimated by tablet counts at each scheduled visit. Random samples of urine aliquots obtained by the adherence team and at the 6- and 24-month visits were frozen at $-20^{\circ} \mathrm{C}$. These were tested for the presence of acyclovir by high-performance liquid chromatography15 at an independent laboratory in the United Kingdom.

Participants who were HIV-positive at screening or who had undergone seroconversion during the trial and who chose to know their HIV status through voluntary counseling and testing were referred to HIV care and treatment centers. Free antiretroviral therapy became available in regional and district hospitals in the study area during the trial. At the end of the trial, funding was provided to allow HIV-positive participants to travel to their care and treatment center for the next 12 to 18 months. Participants who became pregnant during follow-up were referred to the nearest antenatal clinic.

\section{LABORATORY METHODS}

Serum samples obtained during screening were tested for HSV-2 using a type-specific IgG enzyme-linked immunosorbent assay (ELISA) (Kalon Biologicals). HIV testing of blood samples obtained at baseline and during follow-up was performed using the Murex $\mathrm{HIV} \mathrm{Ag}$ / $\mathrm{Ab}$ Combination ELISA (Murex Biotech) and the Uni-Form II Ag/Ab micro ELISA system (bioMérieux BV). Samples with discordant or indeterminate results were retested. If results were not resolved on retesting, the sample was tested by HIV-1 p24 antigen enzyme immunoassay (Biorad Genetic Systems). If the result was positive, it was considered to be the final result. Samples with p24 antigen-negative or indeterminate results and all samples from participants who had undergone seroconversion were tested by a line immunoassay (INNO-LIA HIV I/II, Innogenetics), and the results of the line immunoassay were taken as 
definitive. Participants were assessed for other genital tract infections including syphilis, Trichomonas vaginalis, Chlamydia trachomatis, and Neisseria gonorrhoeae; if ulcers were present, tests for HSV, syphilis, and Haemophilis ducreyi were performed (see the Supplementary Appendix, available with the full text of this article at www.nejm.org).

\section{STATISTICAL ANALYSIS}

The initial sample-size calculation assumed an HIV incidence of 10 per 100 person-years in the placebo group, with $80 \%$ power to detect a $50 \%$ reduction in HIV incidence, based on a two-sided type 1 error rate of 5\%. Under this assumption, 941 person-years of follow-up among HIV-negative participants was required, which was equivalent to following 600 HIV-negative participants for 2 years, with a $15 \%$ loss of person-years over the 2-year period. The assumed incidence rate was based on results from a similar cohort in Mbeya, Tanzania.16 An independent data monitoring committee performed periodic reviews of adverse events and one interim analysis at 12 months, at which the committee noted that the pregnancy rate was higher and the incidence of infection with HIV lower than anticipated. There were no formal rules for stopping on the basis of efficacy or futility. Given the blinded HIV-incidence results at the interim analysis, the trial steering committee recommended that the sample size be increased to 821 and the follow-up period extended to 30 months for 618 participants already enrolled (phases 1 and 2), with a 12-month follow-up period for 203 newly enrolled participants (phase 3).

Data were double-entered and verified in Dbase-IV (dataBased Intelligence). Analyses were conducted with the use of Stata software, version 10.0 (StataCorp). The analysis plan was finalized before completion of the trial and was approved by the data monitoring committee. For the primary modified intention-to-treat analyses, participants were included until the earliest of the following points: the end of the follow-up period (30 months for those in phases 1 and 2 or 12 months for those in phase 3), the date of the first positive pregnancy test, the date on which the participant was last seen, or the estimated date of HIV seroconversion, taken as the midpoint between the last negative and the first positive tests for HIV. Rates of HIV infection in the acyclovir and placebo groups were compared and unadjusted rate ratios were calculated, using Poisson regression. Logistic regression was used to assess the effect of treatment with acyclovir on detection of genital ulcers and cervicovaginal HSV DNA during follow-up.

Secondary analyses comprised an intention-to-treat analysis; an on-treatment analysis, in which data for participants who stopped taking tablets for any reason were censored from the time of withdrawal; and a prespecified on-treatment analysis stratified by estimated adherence within each 3-month period. If a participant did not bring back unused tablets or if she brought back too few tablets and reported that tablets had been lost, stolen, or damaged, adherence was classified as unknown. If a participant missed a visit, then adherence was calculated at her next visit and was based on the number of days that had elapsed since her last visit. A test for trend was used to assess whether the rate ratio for acyclovir versus placebo varied with reported adherence. No subgroup analyses were performed.

The study protocol was approved by the London School of Hygiene and Tropical Medicine ethics committee and by the Medical Research Coordinating Committee of Tanzania. Trial monitoring was done by the United Kingdom Medical Research Council Clinical Trials Unit. Acyclovir and placebo tablets were purchased from Ranbaxy. 


\section{RESULTS}

A total of 2719 females were screened, and 821 HIV-negative females were enrolled (421 in the placebo group and 400 in the acyclovir group) (Fig. 1) between January 2004 and May 2006. Participant characteristics at baseline, including the prevalence of other infections of the reproductive tract, were similar in the two study groups (Table 1). The median age was 28 years. Overall, $41 \%$ of participants reported having used a condom at last sexual intercourse, and 37\% reported having had sex in exchange for money or gifts in the past 3 months (34\% in the placebo group and $40 \%$ in the acyclovir group). A history of genital ulceration or blisters was reported by $25 \%$ of participants, and an ulcer or a blister was seen on examination in $2 \%$.

Overall, 679 participants (83\%) completed follow-up for the primary modified intention-totreat analysis, with similar follow-up time in both groups (1.52 years in the placebo group and 1.62 years in the acyclovir group, $\mathrm{P}=0.58$ by the Wilcoxon rank-sum test). For the primary analysis, data for 165 participants (20\%) were censored because of pregnancy (19\% in the placebo group and $21 \%$ in the acyclovir group) (Fig. 1 and Table 2).

\section{EFFECT OF ACYCLOVIR ON HIV INCIDENCE}

For the primary modified intention-to-treat analysis (Table 3), there were 28 HIV seroconversions in the placebo group and 27 in the acyclovir group. The incidence of infection with HIV was 4.12 per 100 person-years in the placebo group and 4.44 per 100 person-years in the acyclovir group. There was no evidence of an effect of treatment with acyclovir on the incidence of HIV infection (rate ratio, 1.08; 95\% confidence interval [CI], 0.64 to 1.83 ) (Fig. 2). The intention-to-treat analysis showed similar results (rate ratio, 1.01; $95 \%$ CI, 0.61 to 1.66 ), as did the on-treatment analysis (rate ratio, $1.12 ; 95 \% \mathrm{CI}, 0.66$ to 1.90). When the analysis was stratified by reported adherence during each 3 -month period of follow-up, the estimated rate ratio for acyclovir was smaller than 1 for the high-adherence category and increased with lower adherence, but neither the trend nor any of the withincategory rate ratios were statistically significant. Reported adherence was similar in the acyclovir and placebo groups, with at least $90 \%$ adherence reported during $51 \%$ and $52 \%$ of person-years, respectively.

In a total of 144 tested urine samples from participants in the acyclovir group, between 33\% and $67 \%$ had evidence of acyclovir, as compared with 5\% of 146 samples tested from those in the placebo group (Table 4).

\section{REPORTED SEXUAL BEHAVIOR, EPISODES OF GENITAL ULCERATION, AND HSV SHEDDING DURING FOLLOW-UP}

The proportion of visits at which participants reported having had more than one sexual partner in the preceding 3 months was $25 \%$ in the placebo group and $28 \%$ in the acyclovir group (odds ratio, $1.17 ; 95 \% \mathrm{CI}, 0.92$ to 1.48 ). Participants in the placebo group were slightly less likely to report having had sex in exchange for money or gifts than were those in the acyclovir group (24\% vs. $27 \%$; odds ratio for the acyclovir group, 1.15; 95\% CI, 0.91 to 1.45). Adjustment for these factors made little difference to the rate ratio for the acyclovir group (1.06; 95\% CI, 0.62 to 1.79, adjusted for number of partners; and 1.05; 95\% CI, 0.62 to 1.79 , adjusted for partners with exchange of money or gifts).

On examination at scheduled study visits, there were six episodes of genital ulceration or blisters in the placebo group as compared with nine episodes in the acyclovir group (odds ratio for the acyclovir group, $1.69 ; 95 \%$ CI, 0.61 to 4.70 ). Among participants with such episodes, HSV was detected in three in the placebo group and in one in the acyclovir group. 
In cervicovaginal lavage specimens analyzed from a random sample of 450 participants at 6 , 12 , and 24 months, HSV DNA was detected in $4.7 \%$ of samples in the placebo group and in $3.8 \%$ of samples in the acyclovir group (odds ratio for the acyclovir group, $0.82 ; 95 \% \mathrm{CI}$, 0.41 to 1.63 ). A stronger effect was seen among participants with at least $90 \%$ adherence to treatment during the preceding 3-month period (5.0\% for placebo vs. $1.7 \%$ for acyclovir; odds ratio for acyclovir, $0.35 ; 95 \% \mathrm{CI}, 0.10$ to 1.24 ).

\section{ADVERSE EVENTS}

Serious adverse events were documented in 86 participants $(10.5 \%$; 42 in the placebo group and 44 in the acyclovir group) (Table 5). The most common serious adverse event was hospitalization, primarily for malaria. One participant in the placebo group died from a cause related to alcohol use, and one participant who had withdrawn from the acyclovir group died in childbirth. No serious adverse event was attributed to acyclovir.

\section{DISCUSSION}

Biologic and epidemiologic studies have demonstrated strong synergy between HSV-2 and HIV.8-10,17-20 It is therefore plausible that therapy to suppress HSV might reduce HIV acquisition. However, we found no significant effect of twice-daily treatment with acyclovir on the incidence of HIV infection among the participants in our study.

Possible explanations for the lack of effect include chance, limited power to detect moderate effects, bias due to losses to follow-up, and suboptimal adherence to treatment, or the acyclovir regimen (400 mg twice daily) may not be potent enough to fully suppress HSV-2 at the cellular level, especially if any dose is delayed.

Participants lost to follow-up in both groups were more likely to be younger and to consume 10 or more alcoholic drinks per week. Both of these were independent risk factors for HIV infection during the trial (results not shown). It is therefore possible that the overall incidence of infection with HIV in the trial was underestimated and that this bias may have been slightly greater in the acyclovir group. In this case, the true rate ratio would be slightly higher and the main qualitative conclusions of the study would be unchanged.

This was a proof-of-concept trial, and we chose a standard suppressive acyclovir treatment regimen that has been shown to have an efficacy against HSV shedding similar to that of valacyclovir (500 mg twice daily).21 HSV-2 infection is characterized by frequent subclinical reactivations as well as clinical episodes, 22 and recent evidence shows that it acts at the cellular level to potentiate HIV target cells. 23 We considered it theoretically possible that partial suppression of HSV-2 might have an effect on the risk of HIV acquisition. However, the short half-life and poor absorption of acyclovir may mean that plasma levels are not sufficient or are not maintained at a level high enough to switch off this cellular trigger, especially if adherence is suboptimal. In contrast, oral valacyclovir is more readily absorbed, has higher trough plasma acyclovir levels, and leads to greater bioavailability of acyclovir, with a half-life of 2.62 to 3.13 hours.24,25 Several trials of suppressive therapy with valacyclovir (500 mg twice daily) found significant reductions in genital and plasma HIV over periods of up to 3 months.11-14 A trial of acyclovir (800 mg twice daily) in Thailand found a significant effect on genital HIV viral load,26 and there was a significant reduction in plasma HIV and frequency (but not quantity) of genital HIV in a trial of acyclovir (400 mg twice daily) in South Africa.12 In contrast, no effect was found for this dose of acyclovir among HIV-positive participants in our trial.27 These results suggest that valacyclovir (500 $\mathrm{mg}$ twice daily) or a higher dose of acyclovir may be necessary to reduce the replication of HSV-2 in populations in which adherence to treatment is suboptimal. 
The median adherence according to counting of tablets was $90 \%$. Adherence proved challenging to measure. The main limitation of counting was that if participants did not bring back their tablet boxes, or if they reported that tablets had been lost, stolen, or damaged, an accurate estimate of adherence was not possible. Even if participants did return their boxes, they could have discarded tablets before attending a visit. Because of these limitations, we also used a biologic marker of adherence by testing for the presence of acyclovir in urine samples from a sample of participants. A substantial proportion of participants in the acyclovir group did not have any acyclovir detectable, a finding that implies that it had been more than 12 hours since the participants had taken a dose. We also found evidence that a small number of participants in the placebo group had exchanged tablets with participants in the acyclovir group, and this was most apparent soon after the start of the trial. However, one or two tablets of acyclovir taken by a small number of participants in the placebo group are unlikely to have affected the overall outcome of the trial, given the drug's short duration of action.

Despite the limitations of the trial, it is unlikely that we have failed to detect a moderate or strong effect of acyclovir on HIV acquisition that would be important at the public health level. This trial underlines the challenges in asking asymptomatic individuals to take tablets to treat one virus (HSV-2) to prevent infection with or shedding of another virus (HIV). Improved adherence at a level that might be required to demonstrate an effect of acyclovir might be achieved by more frequent clinic visits, by the use of electronic monitoring devices that can record the time when a bottle of medication is opened,28,29 or by working with a study population with greater access to health care services and therefore a better understanding of the importance of adherence.

The proportion of participants shedding HSV-2 was low in both groups as compared with the proportions shedding in other recent studies in both HIV-negative and HIV-positive women in Africa.11,12,30,31 Recurrences of HSV-2 episodes are most frequent in the first months and years after primary infection.32,33 Many characteristics of our participants were similar to those of a Nairobi cohort in which HSV-2 was shown to be associated with increased numbers of genital mucosal target cells that may increase susceptibility to HIV infection.23 However, it is possible that our participants had acquired HSV-2 early and had reached a stage at which their HSV-2 infection was not active enough to contribute substantially to the risk of HIV acquisition. A recent meta-analysis demonstrated little overall association between HSV-2 and the acquisition of HIV in high-risk women, 8 and it is conceivable that other risk factors outweigh the influence of HSV-2 on the risk of HIV acquisition in such groups. Our trial was carried out in a population at moderately high risk for acquiring HIV. Therefore, the results may not be applicable to women in the general population.

The results of this trial indicate that, despite good biologic plausibility, acyclovir at a dose of $400 \mathrm{mg}$ twice daily is not a viable public health intervention for preventing infection with HIV. It is possible that the hypothesis that infection with HSV increases HIV acquisition is false, but this seems unlikely, given the strong biologic and epidemiologic evidence for a synergistic effect between HIV and HSV-2. The potential of HSV suppression in HIVpositive subjects for preventing transmission of HIV will be tested in an ongoing multicenter trial among HIV-serodiscordant couples that is scheduled for completion in 2009. The lack of effect of suppressive therapy on HIV acquisition suggests that renewed attention should be given to new strategies of HSV-2 prevention and control to prevent HIV infection. 


\section{Acknowledgments}

Supported by grants from the Wellcome Trust, the United Kingdom Medical Research Council, and the United Kingdom Department of International Development.

We thank the women who participated in the trial; the HSV trial team; Obed Mrita, Fatma Mohammed, Paul Waibale, and Koronel Kema of the African Medical and Research Foundation; the staff of the laboratory, data, and collaborative projects offices of the National Institute for Medical Research (NIMR), Mwanza Centre; David Mabey, Tamara Hurst, and Fiona Marquet of the Wellcome Bloomsbury Centre for Clinical Tropical Medicine; Tobias Chirwa of the London School of Hygiene and Tropical Medicine and NIMR, Mwanza Centre, for statistical support; Anne Buvé, Eddy van Dyck, and Tania Crucetti of the Institute of Tropical Medicine, Antwerp, Belgium, Michel Alary of the University of Laval, Quebec, Canada, and Cecile Lefebvre for advice on the protocol and their help with laboratory assays; and the members of the trial Steering and Data Monitoring Committees.

\section{Appendix}

Investigators: African Medical and Research Foundation, Mwanza, Tanzania - K. Mugeye, D. Watson-Jones (principal investigator); National Institute for Medical Research, Mwanza, Tanzania - K. Baisley, J. Changalucha, D. Everett, L. Knight, C. Tanton; London School of Hygiene and Tropical Medicine, London - K. Baisley, T. Clayton, D. Everett, I. Hambleton, R. Hayes, L. Knight, D. Ross, C. Tanton, D. Watson-Jones, H. Weiss; INSERM Unité 743 and Université Paris V, Paris - L. Belec; Laboratoire de Microbiologie, Hôpital Saint Louis, Paris — J. Le Goff. Trial Steering Committee: Medical Research Council Clinical Trials Unit, London - A. Nunn; University College, London - F. Cowan; Harvard School of Public Health, Boston - S. Kapiga; Ifakara Health Research and Development Centre, Dar es Salaam, Tanzania - H. Mshinda. Data Monitoring Committee: Medical Research Council Clinical Trials Unit, London — D. Dunn; Medical Research Council-Uganda Virus Research Institute, Entebbe, Uganda - H. Grosskurth; Africa Malaria Network Trust, Dar es Salaam, Tanzania - W. Kilama.

\section{References}

1. Joint United Nations Programme on HIV/AIDS. Report on the global AIDS epidemic. 2006Accessed March 8, 2008, at http://www.unaids.org/en/KnowledgeCentre/HIVData/ GlobalReport/.

2. Riedner G, Rusizoka M, Hoffmann O, et al. Baseline survey of sexually transmitted infections in a cohort of female bar workers in Mbeya Region, Tanzania. Sex Transm Infect. 2003; 79:382-7. [PubMed: 14573833]

3. Vallely A, Kasindi S, Hambleton I, et al. Microbicides development program, Tanzania-baseline characteristics of an occupational cohort and reattendance at 3 months. Sex Transm Dis. 2007; 34:638-43. [PubMed: 17717482]

4. Watson-Jones D, Weiss H, Rusizoka M, et al. Risk factors for herpes simplex type 2 and HIV among women at high risk in northwestern Tanzania: preparing for an HSV-2 intervention trial. J Acquir Immune Defic Syndr. 2007; 46:631-42. [PubMed: 18043318]

5. Fonck K, Kaul R, Kimani J, et al. A randomized, placebo-controlled trial of monthly azithromycin prophylaxis to prevent sexually transmitted infections and HIV-1 in Kenyan sex workers: study design and baseline findings. Int J STD AIDS. 2000; 11:804-11. [PubMed: 11138916]

6. Kapiga SH, Sam NE, Shao JF, et al. Herpes simplex virus type 2 infection among bar and hotel workers in northern Tanzania: prevalence and risk factors. Sex Transm Dis. 2003; 30:187-92. [PubMed: 12616132]

7. Wald A, Link K. Risk of human immunodeficiency virus infection in herpes simplex virus type 2seropositive persons: a meta-analysis. J Infect Dis. 2002; 185:45-52. [PubMed: 11756980]

8. Freeman EE, Weiss HA, Glynn JR, Cross PL, Whitworth JA, Hayes RJ. Herpes simplex virus 2 infection increases HIV acquisition in men and women: systematic review and meta-analysis of longitudinal studies. AIDS. 2006; 20:73-83. [PubMed: 16327322] 
9. del Mar Pujades Rodríguez M, Obasi A, Mosha F, et al. Herpes simplex virus type 2 infection increases HIV incidence: a prospective study in rural Tanzania. AIDS. 2002; 16:451-62. [PubMed: 11834958]

10. Kapiga SH, Sam NE, Bang H, et al. The role of herpes simplex virus type 2 and other genital infections in the acquisition of HIV-1 among high-risk women in northern Tanzania. J Infect Dis. 2007; 195:1260-9. [PubMed: 17396994]

11. Nagot N, Ouédraogo A, Foulongne V, et al. Reduction of HIV-1 RNA levels with therapy to suppress herpes simplex virus. N Engl J Med. 2007; 356:790-9. [PubMed: 17314338]

12. Delany, S.; Mayaud, P.; Clayton, T., et al. Impact of HSV-2 suppressive therapy on genital and plasma HIV-1 RNA in HIV-1 and HSV-2 seropositive women not taking ART: a randomized placebo-controlled trial in Johannesburg, South Africa; Presented at the 14th Conference on Retroviruses and Opportunistic Infections; Los Angeles. February 25-28, 2007; abstract

13. Baeten, JM.; Strick, LB.; Lucchetti, A., et al. Herpes simplex virus suppressive treatment decreases plasma HIV-1 viral load in HSV-2/HIV-1 co-infected women: a randomised, placebo-controlled, cross-over trial; Presented at the 17th International Society for Sexually Transmitted Diseases Research Meeting; Seattle. July 29-August 1, 2007; abstract

14. Zuckerman RA, Lucchetti A, Whittington WL, et al. Herpes simplex virus (HSV) suppression with valacyclovir reduces rectal and blood plasma HIV-1 levels in HIV-1/HSV-2-seropositive men: a randomized double-blind placebo-controlled crossover trial. J Infect Dis. 2007; 196:1500-8. [PubMed: 18008230]

15. Loregian A, Gatti R, Palu G, De Palo EF. Separation methods for acyclovir and related antiviral compounds. J Chromatogr B Biomed Sci Appl. 2001; 764:289-311. [PubMed: 11817033]

16. Riedner, G.; Rusizoka, M.; Hoelscher, M., et al. Studies on the interaction between STI and HIV in the context of the new HIV superinfection study (HISIS) among bar-workers in Mbeya, Tanzania; Presented at the 14th International Society for Sexually Transmitted Diseases Research Meeting; Berlin. June 24-27, 2001;

17. Obasi A, Mosha F, Quigley M, et al. Antibody to herpes simplex virus type 2 as a marker of sexual risk behaviour in rural Tanzania. J Infect Dis. 1999; 179:16-24. [PubMed: 9841817]

18. Gwanzura L, McFarland W, Alexander D, Burke RL, Katzenstein D. Association between human immunodeficiency virus and herpes simplex virus type 2 seropositivity among male factory workers in Zimbabwe. J Infect Dis. 1998; 177:481-4. [PubMed: 9466543]

19. Schacker T, Zeh J, Hu H, Hill E, Corey L. Frequency of symptomatic and asymptomatic herpes simplex virus type 2 reactivations among human immunodeficiency virus-infected men. J Infect Dis. 1998; 178:1616-22. [PubMed: 9815213]

20. Chen CY, Ballard RC, Beck-Sague CM, et al. Human immunodeficiency virus infection and genital ulcer disease in South Africa: the herpetic connection. Sex Transm Dis. 2000; 27:21-9. [PubMed: 10654864]

21. Gupta R, Wald A, Krantz E, et al. Valacyclovir and acyclovir for suppression of shedding of herpes simplex virus in the genital tract. J Infect Dis. 2004; 190:1374-81. [PubMed: 15378428]

22. Mark, KE.; Wald, AS.; Magaret, S., et al. Rapid onset and clearance of genital HSV reactivations in immunocompetent adults: the virus is usually "on."; Presented at 17th International Society for Sexually Transmitted Diseases Research Meeting; Seattle. July 29-August 1, 2007; abstract

23. Rebbapragada A, Wachihi C, Pettengell C, et al. Negative mucosal synergy between Herpes simplex type 2 and HIV in the female genital tract. AIDS. 2007; 21:589-98. [PubMed: 17314521]

24. Conant MA, Schacker TW, Murphy RL, et al. Valaciclovir versus aciclovir for herpes simplex virus infection in HIV-infected individuals: two randomized trials. Int J STD AIDS. 2002; 13:1221. [PubMed: 11802924]

25. Perry CM, Faulds D. Valaciclovir: a review of its antiviral activity, pharmacokinetic properties and therapeutic efficacy in herpesvirus infections. Drugs. 1996; 52:754-72. [PubMed: 9118821]

26. Dunne, E.; Whitehead, S.; Sternberg, M., et al. The effect of suppressive acyclovir therapy on HIV cervicovaginal shedding in HIV- and HSV-2-infected women, Chiang Rai, Thailand; Presented at the 14th Conference on Retroviruses and Opportunistic Infections; Los Angeles. February 25-28, 2007; abstract 
27. Tanton, C.; Watson-Jones, D.; Rusizoka, M., et al. A randomized controlled trial in Tanzania to assess the impact of HSV2 suppressive therapy on genital HIV viral load among HSV2 and HIV1 seropositive women; Presented at the International AIDS Society Conference; Sydney. July 22-25, 2007; abstract

28. Vriesendorp R, Cohen A, Kristanto P, et al. Adherence to HAART therapy measured by electronic monitoring in newly diagnosed HIV patients in Botswana. Eur J Clin Pharmacol. 2007; 63:111521. [PubMed: 17882408]

29. Hayes, TL.; Hunt, JM.; Adami, A.; Kaye, JA. An electronic pillbox for continuous monitoring of medication adherence; Proceedings of the 27th Annual International Conference of the IEEE Engineering in Medicine and Biology Society; New York. August 30-September 3; Accessed March 8, 2008, at http://www.bme.ogi.edu/POCL/publications/MedTracker_EMBS_2006.pdf.

30. Mbopi-Keou F-X, Gresenguet G, Mayaud P, et al. Interactions between herpes simplex virus type 2 and human immunodeficiency virus type 1 infection in African women: opportunities for intervention. J Infect Dis. 2000; 182:1090-6. [PubMed: 10979904]

31. Cowan FF, Pascoe SJ, Barlow KL, et al. Association of genital shedding of herpes simplex virus type 2 and HIV-1 among sex workers in rural Zimbabwe. AIDS. 2006; 20:261-7. [PubMed: 16511420]

32. Benedetti JK, Zeh J, Corey L. Clinical reactivation of genital herpes simplex virus infection decreases in frequency over time. Ann Intern Med. 1999; 131:14-20. [PubMed: 10391810]

33. Koelle DM, Benedetti J, Langenberg A, Corey L. Asymptomatic reactivation of herpes simplex virus shedding in women after the first episode of genital herpes. Ann Intern Med. 1992; 116:4337. [PubMed: 1310837] 


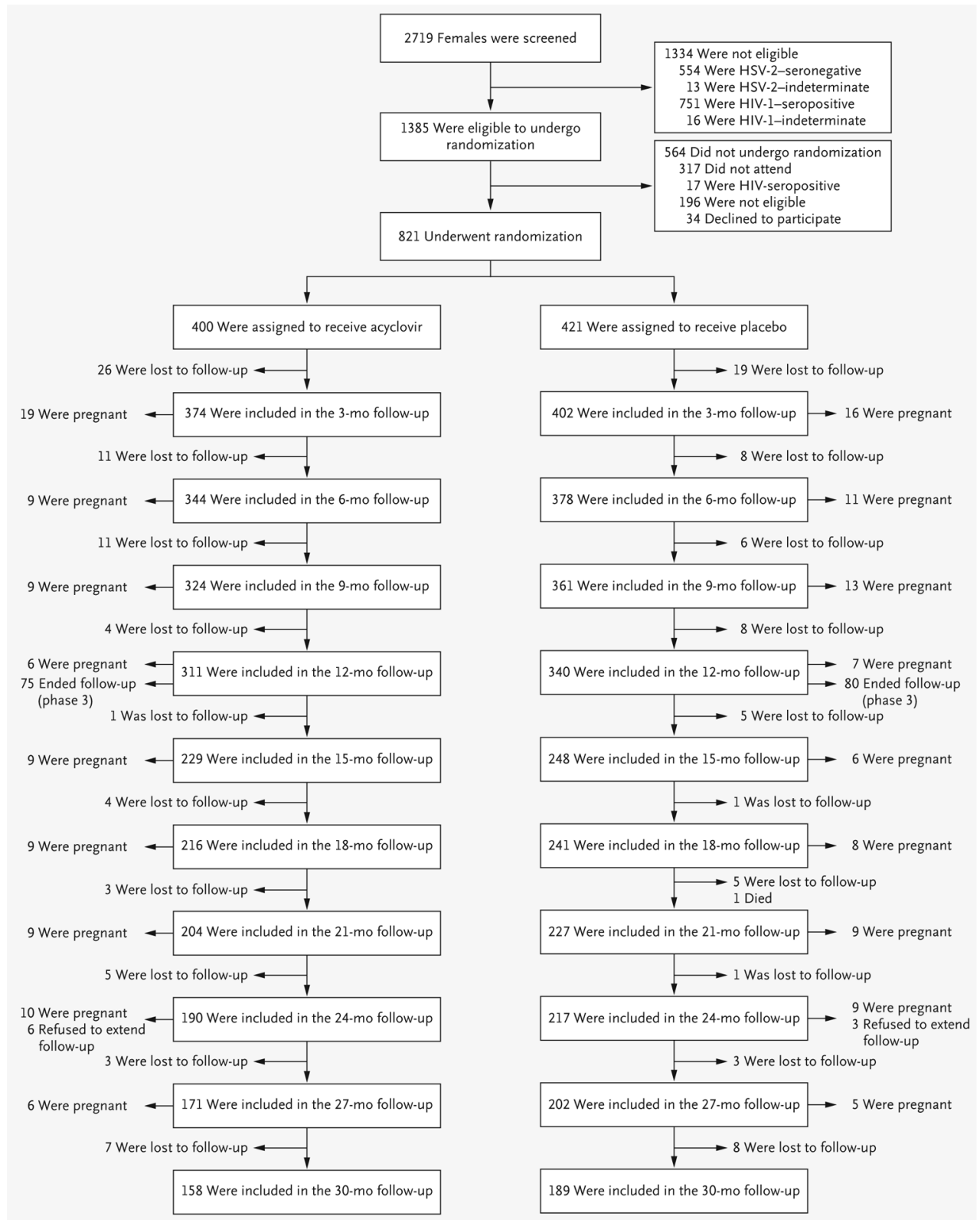

Figure 1.

Screening, Randomization, and Follow-up of Study Participants. 


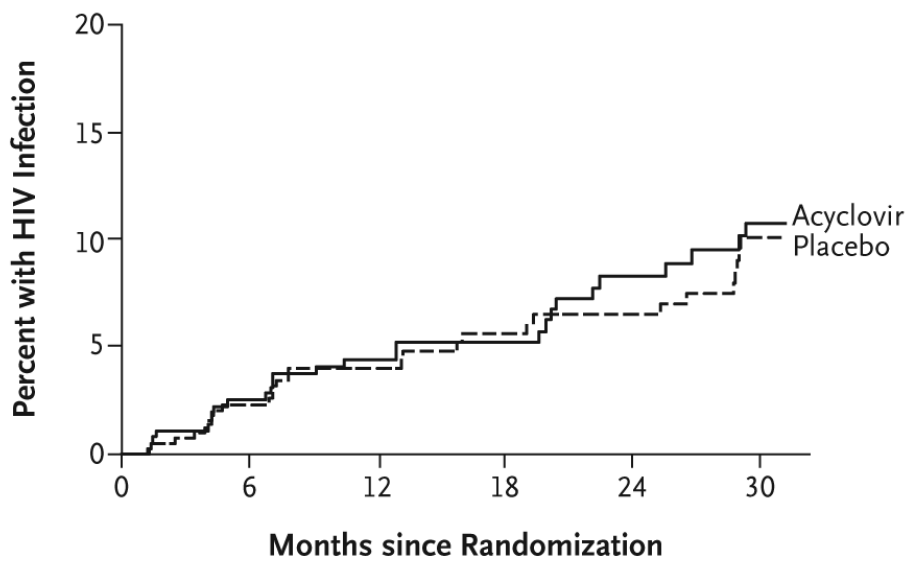

No. at Risk

$\begin{array}{lllllll}\text { Acyclovir } & 400 & 324 & 246 & 195 & 166 & 137\end{array}$

$\begin{array}{lllllll}\text { Placebo } & 421 & 356 & 267 & 217 & 199 & 162\end{array}$

Figure 2.

Kaplan-Meier Estimates of the Cumulative Percentage of Patients with HIV Infection, According to Study Group. 
Table 1

Baseline Characteristics of the Participants.

\begin{tabular}{|c|c|c|c|}
\hline Characteristic & $\begin{array}{r}\text { Acyclovir Group } \\
\qquad(\mathrm{N}=\mathbf{4 0 0})\end{array}$ & $\begin{array}{r}\text { Placebo Group } \\
(\mathbf{N}=\mathbf{4 2 1})\end{array}$ & $\begin{array}{r}\text { Total } \\
(\mathbf{N}=\mathbf{8 2 1})\end{array}$ \\
\hline \multicolumn{4}{|l|}{ Age - yr } \\
\hline Median & 28 & 27 & 28 \\
\hline Interquartile range & $23-32$ & $23-31$ & $23-32$ \\
\hline \multicolumn{4}{|l|}{ Age - no. $(\%)$} \\
\hline $16-19 \mathrm{yr}$ & $25(6)$ & $25(6)$ & $50(6)$ \\
\hline $20-24 \mathrm{yr}$ & $94(24)$ & $104(25)$ & $198(24)$ \\
\hline $25-29 \mathrm{yr}$ & $113(28)$ & $137(33)$ & $250(30)$ \\
\hline $30-35 \mathrm{yr}$ & $168(42)$ & $155(37)$ & $323(39)$ \\
\hline \multicolumn{4}{|l|}{ Marital status - no. $(\%)$} \\
\hline Unmarried & $78(20)$ & $87(21)$ & $165(20)$ \\
\hline Married or living as married & $111(28)$ & $127(30)$ & $238(29)$ \\
\hline Divorced or separated & $192(48)$ & $192(46)$ & $384(47)$ \\
\hline Widowed & $19(5)$ & $15(4)$ & $34(4)$ \\
\hline \multicolumn{4}{|l|}{ Educational level - no. (\%) } \\
\hline Less than primary & $120(30)$ & $137(33)$ & $257(31)$ \\
\hline Primary & $260(65)$ & $262(62)$ & $522(64)$ \\
\hline Secondary & $20(5)$ & $22(5)$ & $42(5)$ \\
\hline \multicolumn{4}{|l|}{ Type of work or work facility — no. (\%) } \\
\hline Local food handler & $215(54)$ & $223(53)$ & $438(53)$ \\
\hline Guesthouse & $44(11)$ & $47(11)$ & $91(11)$ \\
\hline Bar & $48(12)$ & $55(13)$ & $103(13)$ \\
\hline Local brew seller & $27(7)$ & $30(7)$ & $57(7)$ \\
\hline Restaurant, cafe, or grocery & $66(16)$ & $66(16)$ & $132(16)$ \\
\hline \multicolumn{4}{|l|}{ Type of site - no. (\%) } \\
\hline Trading center & $102(26)$ & $118(28)$ & $220(27)$ \\
\hline Mining town & $82(20)$ & $81(19)$ & $163(20)$ \\
\hline Truck stop & $216(54)$ & $222(53)$ & $438(53)$ \\
\hline \multicolumn{4}{|l|}{ Travel in past 3 months - no. (\%) } \\
\hline None & $276(69)$ & $306(73)$ & $582(71)$ \\
\hline$<1$ wk total & $28(7)$ & $29(7)$ & $57(7)$ \\
\hline$\geq 1$ trip lasting $>1 \mathrm{wk}$ & $96(24)$ & $86(20)$ & $182(22)$ \\
\hline \multicolumn{4}{|c|}{ Number of sexual partners in past $3 \mathrm{mo}-$ no. $(\%)$} \\
\hline 0 & $44(11)$ & $35(8)$ & $79(10)$ \\
\hline 1 & $222(56)$ & $240(57)$ & $462(56)$ \\
\hline $2-3$ & $104(26)$ & 120 (29) & $224(27)$ \\
\hline$\geq 4$ & $30(8)$ & $26(6)$ & $56(7)$ \\
\hline \multicolumn{4}{|l|}{ Sexual partners in lifetime - no. (\%) } \\
\hline $0-1$ & $21(5)$ & $12(3)$ & $33(4)$ \\
\hline $2-4$ & $156(39)$ & $158(38)$ & $314(38)$ \\
\hline
\end{tabular}




\begin{tabular}{|c|c|c|c|}
\hline Characteristic & $\begin{array}{r}\text { Acyclovir Group } \\
\qquad(\mathbf{N}=\mathbf{4 0 0})\end{array}$ & $\begin{array}{r}\text { Placebo Group } \\
\qquad(\mathbf{N}=\mathbf{4 2 1})\end{array}$ & $\begin{array}{r}\text { Total } \\
(\mathbf{N}=\mathbf{8 2 1})\end{array}$ \\
\hline $5-9$ & $133(33)$ & $153(36)$ & $286(35)$ \\
\hline $10-24$ & $67(17)$ & $81(19)$ & $148(18)$ \\
\hline$\geq 25$ & $23(6)$ & $17(4)$ & $40(5)$ \\
\hline \multicolumn{4}{|c|}{$\begin{array}{l}\text { Sexual partners with whom sex was exchanged for } \\
\text { gifts or money in past } 3 \mathrm{mo}-\text { no. }(\%)\end{array}$} \\
\hline 0 & $241(60)$ & $278(66)$ & $519(63)$ \\
\hline 1 & $111(28)$ & $97(23)$ & $208(25)$ \\
\hline $2-3$ & $40(10)$ & $38(9)$ & $78(10)$ \\
\hline$\geq 4$ & $8(2)$ & $8(2)$ & $16(2)$ \\
\hline \multicolumn{4}{|l|}{ Condom use - no. $(\%)$} \\
\hline Never & $85(21)$ & $85(20)$ & $170(21)$ \\
\hline Sometimes & $171(43)$ & $178(42)$ & $349(43)$ \\
\hline Often & $73(18)$ & $67(16)$ & $140(17)$ \\
\hline Always & $71(18)$ & $91(22)$ & $162(20)$ \\
\hline \multicolumn{4}{|c|}{ Condom use during most recent sexual act - no. $(\%)$} \\
\hline No & $164(41)$ & $173(41)$ & $337(41)$ \\
\hline Yes & $236(59)$ & $248(59)$ & $484(59)$ \\
\hline \multicolumn{4}{|l|}{ Alcoholic drinks/wk - no. (\%) } \\
\hline 0 & $198(50)$ & $213(51)$ & $411(50)$ \\
\hline $1-4$ & $97(24)$ & $102(24)$ & $199(24)$ \\
\hline $5-9$ & $40(10)$ & $33(8)$ & $73(9)$ \\
\hline $10-19$ & $22(6)$ & $40(10)$ & $62(8)$ \\
\hline 20 & $43(11)$ & $33(8)$ & $76(9)$ \\
\hline \multicolumn{4}{|c|}{ Medical injection within past $5 \mathrm{yr}-$ no. (\%) } \\
\hline No & $92(23)$ & $124(29)$ & $216(26)$ \\
\hline Yes & $308(77)$ & $297(71)$ & $605(74)$ \\
\hline \multicolumn{4}{|c|}{ Receipt of blood transfusion - no. (\%) } \\
\hline Never & $351(88)$ & $385(92)$ & $736(90)$ \\
\hline Ever & $49(12)$ & $35(8)$ & $84(10)$ \\
\hline \multicolumn{4}{|c|}{ Neisseria gonorrhoeae infection — no. (\%) } \\
\hline No & $381(95)$ & $405(96)$ & $786(96)$ \\
\hline Yes & $19(5)$ & $16(4)$ & $35(4)$ \\
\hline \multicolumn{4}{|c|}{ Chlamydia trachomatis infection - no. $(\%)$} \\
\hline No & $371(93)$ & $388(92)$ & $759(92)$ \\
\hline Yes & $29(7)$ & $33(8)$ & $62(8)$ \\
\hline \multicolumn{4}{|l|}{ Active syphilis - no. $(\%)^{*}$} \\
\hline No & $344(86)$ & $372(88)$ & $716(87)$ \\
\hline Yes & $56(14)$ & $49(12)$ & $105(13)$ \\
\hline \multicolumn{4}{|l|}{ Bacterial vaginosis } \\
\hline No or intermediate & $174(44)$ & $164(39)$ & $338(41)$ \\
\hline Yes & $226(57)$ & $257(61)$ & $483(59)$ \\
\hline
\end{tabular}




\begin{tabular}{|crrr|}
\hline Characteristic & $\begin{array}{r}\text { Acyclovir Group } \\
(\mathbf{N}=\mathbf{4 0 0})\end{array}$ & $\begin{array}{r}\text { Placebo Group } \\
(\mathbf{N}=\mathbf{4 2 1})\end{array}$ & $\begin{array}{r}\text { Total } \\
(\mathbf{N}=\mathbf{8 2 1})\end{array}$ \\
& $284(71)$ & $312(74)$ & $596(73)$ \\
No & $114(29)$ & $108(26)$ & $222(27)$ \\
\hline
\end{tabular}

* Data for receipt of blood transfusion were missing for one participant in the placebo group and for Trichomonas vaginalis infection were missing for two participants in the acyclovir group and one participant in the placebo group. Active syphilis was defined by a positive rapid plasma reagin test and either a positive Treponema pallidum particle agglutination assay or a positive fluorescent treponemal antibody assay. 
Table 2

Summary of Follow-up in the Two Study Groups.

\begin{tabular}{|c|c|c|}
\hline Follow-up Status & $\begin{array}{r}\text { Acyclovir Group } \\
(\mathbf{N}=\mathbf{4 0 0})\end{array}$ & $\begin{array}{r}\text { Placebo Group } \\
(N=421)\end{array}$ \\
\hline \multicolumn{3}{|l|}{ Modified intention-to-treat analysis - no. (\%) } \\
\hline Completed follow-up & $212(53)$ & $247(59)$ \\
\hline Was lost to follow-up & $78(20)$ & $64(15)$ \\
\hline Became pregnant & $83(21)$ & $82(19)$ \\
\hline Had HIV seroconversion & $27(7)$ & $28(7)$ \\
\hline \multicolumn{3}{|l|}{ Intention-to-treat analysis - no. $(\%)$} \\
\hline Completed follow-up & $280(70)$ & $316(75)$ \\
\hline Was lost to follow-up & $90(23)$ & $72(17)$ \\
\hline Had HIV seroconversion & $30(8)$ & $33(8)$ \\
\hline \multicolumn{3}{|l|}{ On-treatment analysis — no. $(\%)$} \\
\hline Completed follow-up & $212(53)$ & $246(58)$ \\
\hline Was lost to follow-up & $58(14)$ & $51(12)$ \\
\hline Became pregnant & $81(20)$ & $81(19)$ \\
\hline Withdrew for other reasons & $22(6)$ & $16(4)$ \\
\hline Had HIV seroconversion & $27(7)$ & $27(6)$ \\
\hline Modified intention-to-treat analysis — person-yr of follow-up & 607 & 680 \\
\hline Intention-to-treat analysis — person-yr of follow-up & 699 & 777 \\
\hline On-treatment analysis - person-yr of follow-up & 605 & 676 \\
\hline \multicolumn{3}{|c|}{ On-treatment analysis, according to level of adherence — person-yr of follow-up (\%) ${ }^{*}$} \\
\hline$凶 00 \%$ & $318(52)$ & $348(51)$ \\
\hline 75 to $<90 \%$ & $97(16)$ & $126(19)$ \\
\hline$<75 \%$ & $90(15)$ & $89(13)$ \\
\hline Unknown & $101(15)$ & $113(17)$ \\
\hline
\end{tabular}

Level of adherence was estimated on the basis of tablet count for each 3-month period of observation. 


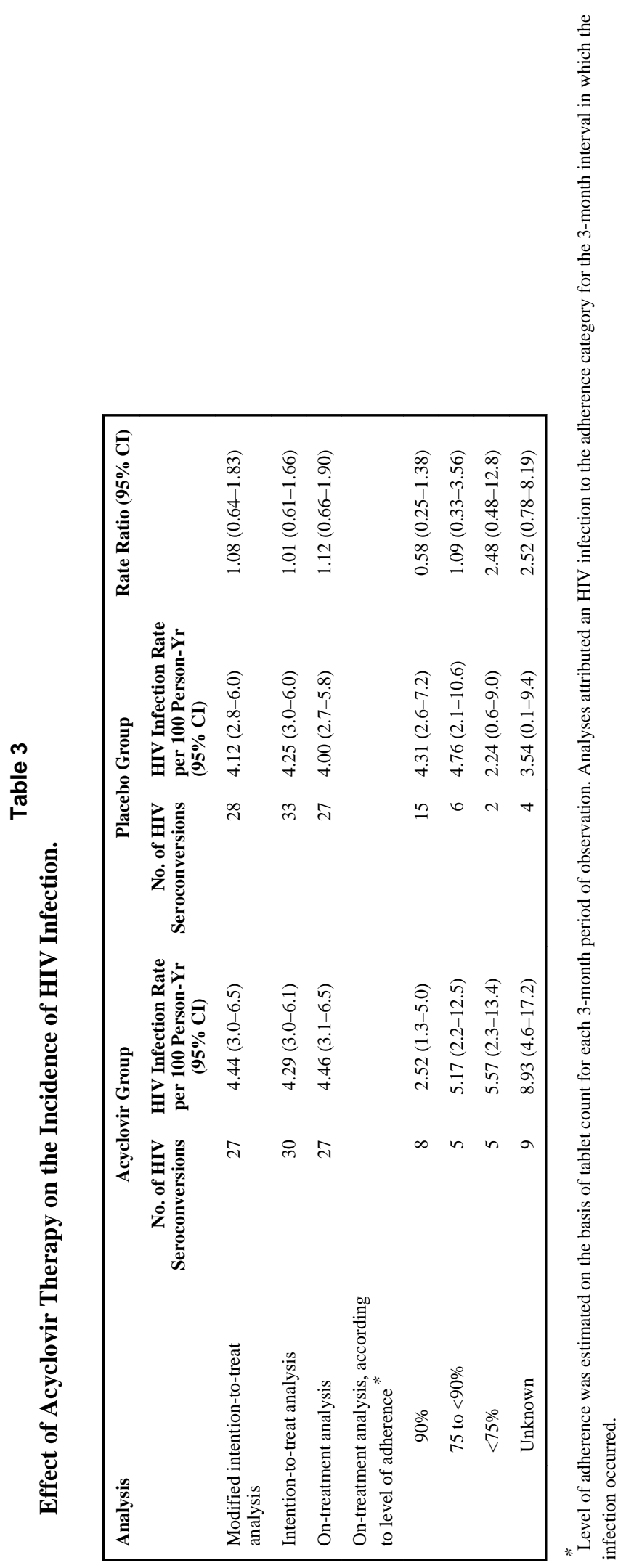

NEngl J Med. Author manuscript; available in PMC 2009 February 16. 


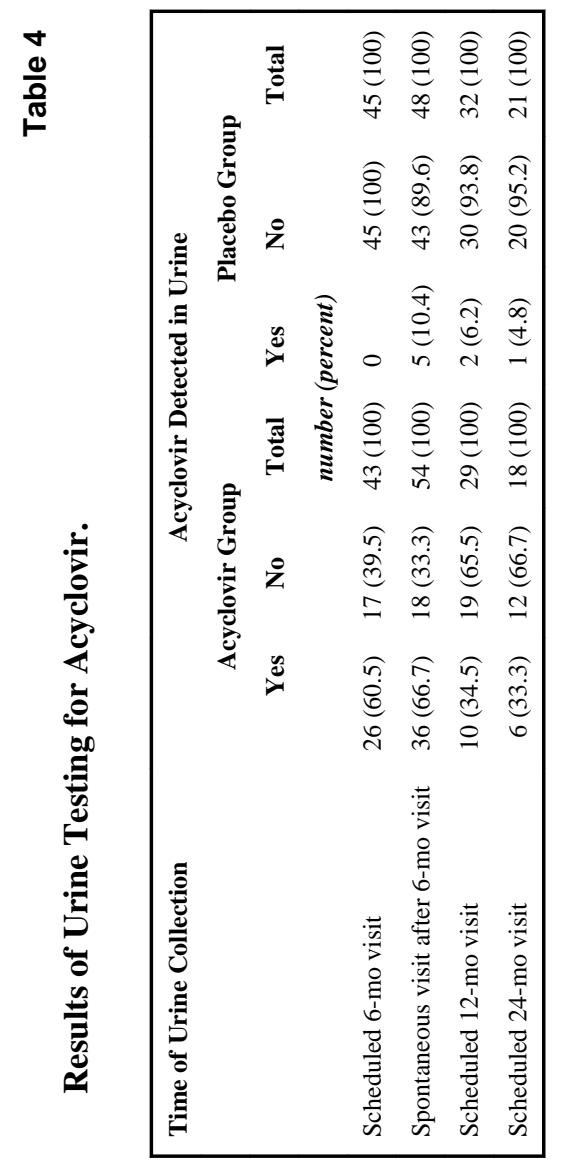

N Engl J Med. Author manuscript; available in PMC 2009 February 16. 
Table 5

Serious Adverse Events.

\begin{tabular}{|lll|}
\hline Event & $\begin{array}{l}\text { Acyclovir Group } \\
(\mathbf{N}=\mathbf{4 0 0})\end{array}$ & $\begin{array}{l}\text { Placebo Group } \\
(\mathbf{N}=\mathbf{4 2 1})\end{array}$ \\
Total no. of events & 49 & no. $(\%)$ \\
Participants with $\geq 1$ event & $44(11.0)$ & 46 \\
Death & $1(0.2)$ & $42(10.0)$ \\
Life-threatening illness & $6(1.5)$ & $1(0.2)$ \\
Hospitalization & $38(9.5)$ & $8(1.9)$ \\
Persistent disability & 0 & $34(8.1)$ \\
Congenital abnormality & 0 & $1(0.2)$ \\
\hline
\end{tabular}

See the Supplementary Appendix for details. 